\title{
Is music a language?:
}

\section{Adorno, Voloshinov and the language character of music}

\author{
Mark Abel
}

Is music a language? Speaking of the 'language of music' seems to capture the sense that we have when listening to them or playing them that musical sounds are meaningful. But is it helpful to understand music in this way, is it consistent with historical materialism to do so, and does it matter?

Clearly, music is much less of a priority as a field for historical materialist theorising than many others. Nevertheless, Marxists are interested in culture and ideology, and in particular in assigning the role of culture its correct place in an overall theorisation of society and social change. It is this positioning of ideas and conceptions, and by extension culture and art, that occupy Marx and Engels in texts that might be considered as foundational of historical materialism, such as The German Ideology. Their main concern there and elsewhere is to refute idealist conceptions of the world which attribute primacy to systems of thought in historical development and change. But this does not mean that they thought such 'superstructural' aspects of society were not worthy of analysis. As Engels put it, Marx's 'discovery' consisted in realising that politics, 
science, art and religion must be explained in the light of 'the degree of economic development attained by a given people or during a given epoch'. ${ }^{1}$ The study of art and culture has been a significant element of Marxist theory ever since.

The problem we have with music is that, of all the artistic or ideological media, it remains the most afflicted by the persistence of the kind of idealist interpretations that Marx was keen to overturn. The efforts of Marxists to found a historical materialist understanding of music have made only minimal headway against conceptions which regard music either as meaningless, merely background support for words, drama or pictures; or as 'ideal object', the most ethereal and least material of cultural phenomena, the manifestation in sound of something like pure thought. $^{2}$

This is where a comparison with language might be productive. The conception of language as pure idea was one that Marx and Engels challenged directly in The German Ideology. Thought, or 'spirit', is always 'burdened by matter', they insisted; and it is clear that music

\footnotetext{
${ }^{1}$ Marx and Engels 1962, p. 263 (Selected Works in Two Volumes, Lawrence \& Wishart

${ }^{2}$ A third conception, deriving from ethnomusicology and not addressed here, avoids the pitfall of regarding music as a medium for carrying messages, but only at the expense of short-circuiting the question of meaning by equating musics with the identity of the peoples with which they are associated; thus the meaning of 'black music' is its 'blackness'.
} 
shares language's dependence on the materiality of 'agitated layers of air', ${ }^{3}$ and is generated by the same human organ ${ }^{4}$ or by our physical action on the world. A materialist understanding of music must begin here, and must also challenge that common notion that there is something less material about hearing than seeing, or touching; that the ear is less sensuous, in Marx's meaning of the term in the 1844 Manuscripts, than the eye. ${ }^{5}$

Nevertheless, the argument that music is, or is like, a language comes from a range of different aesthetic, philosophical and political perspectives, many of which share little with Marxism. It is a view that commonly takes one of two forms. The first takes the claim literally and seeks to identify through textual analysis those elements of music which fulfil the syntactical and grammatical functions of language. As a result, this approach is limited by its tendency to treat 'composed', notated music as a norm, effectively having little to say about anything other than Western art-music of the last 350 years. ${ }^{6}$

The second, more metaphorical, form of the argument is that music has the ability to 'speak' to us in a manner which feels as immediate as

\footnotetext{
${ }^{3}$ Marx and Engels 1970, p. 51

4 i.e. the larynx, see Engels 1934, p. 5

${ }^{5}$ Marx 1973, pp. 51-2

${ }^{6}$ See Riemann 1877 and Schenker 1935.
} 
being addressed in our mother tongue. The modern suggestion that music is the language of emotions shares an affinity with Schopenhauer's nineteenth-century idealist conception of music as the direct expression of the striving of the Will which in turn structures nature and the universe. ${ }^{7}$ Neither of these two approaches is consistent with a historical materialist understanding of music.

Theodor Adorno provides a starting point for a materialist comparison of music and language. Adorno's position certainly has very little affinity with the common ones outlined above. Music, he says, 'never was a language of pure feeling, nor a language of the affirmation of the soul'. Nor would he have accepted the commonplace contemporary assertion that music is a 'universal language', capable of 'bringing people together', since he argues that music's supposed 'intuitability' is always pervaded by the conceptual, which requires an effort of understanding. ${ }^{8}$ Moreover, Adorno's position is complicated by the fact that for him, language-character was not confined to music, but extended to other artforms as well, including those, like painting, which do not unfold in time in the way that music and speech do. Thus, his argument is much more nuanced and ambiguous than most other versions of the music-aslanguage position. In addition, like most of Adorno's aesthetics, his

\footnotetext{
${ }^{7}$ See Cooke 1959 and Schopenhauer 2010.

${ }^{8}$ Adorno 1997, pp. 41, 125
} 
adoption of the standpoint of early twentieth century modernism is a factor which both determines and qualifies it in important ways.

The purpose of this article is to assess the effectiveness of the supposed affinity between music and language for a historical materialist understanding of music. First, it will be necessary to explore Adorno's arguments about the language character of music, and their role within his materialist conception of music more generally. Since that will be of limited use without a clear understanding of what is meant by language itself, we will also compare Adorno's view of language with what remains the classic Marxist theorisation, Valentin Voloshinov's Marxism and the Philosophy of Language of 1929. Adorno and Voloshinov are not obvious bedfellows. Though contemporaries, they occupied very different intellectual worlds and drew on the Marxist tradition in such distinct ways that their intellectual paths never crossed and they are rarely discussed together. Nonetheless, since they shared a concern with language and its role in ideology and culture, it is hoped that juxtaposing them in this way can be productive for illuminating the issue at hand, namely that of musical meaning; that is, the meaning of music itself, independent of any associated words in the form of lyrics or libretti or programme notes. 
What follows will, therefore, seek to elucidate Adorno's thoughts on the language character of music by viewing them through the lens of his own, quite distinctive, understanding of language, setting this discussion within the framework of a broadly Marxist philosophy of language. It will suggest that an analogy with language illuminates perhaps the most important contribution of Adorno to a materialist understanding of music - the historically given nature of musical material; but that a historical materialist grasp of language can serve as a model for avoiding the pitfalls of objectivism and subjectivism in this theory. It will conclude by considering whether Voloshinov's theory of consciousness can be productively extended to music and used to enhance Adorno's conception of music as a form of cognition.

The focus throughout will be on the meaning of music. I do not attempt to attribute meanings to particular works or kinds of music, or to identify some music as more meaningful than other music. Nor is it within the scope of this article to address either the sociology or political economy of music, without which no historical materialist understanding of music in any society could be complete. The purpose here is to address the underlying question of how our sense that music and music-making is meaningful can be justified in materialist terms; that is, without falling 
back on idealist notions that music is a medium for transmitting messages or for expressing the thoughts or emotions of the individual(s) who composed or made it. Since language is, like music, a universal social practice based on the production and perception of sound, it is hoped that the comparison will be instructive, especially since the historical materialist theorisation of language is much more welldeveloped than that of music.

\section{Adorno on the language-character of music}

The discussion in key texts such as 'Music and Language: A Fragment' of 1956 abounds with the kinds of ambiguities and difficulties which bedevil any attempt to read Adorno. Initially, the argument appears to be reasonably straightforward:

Music is like language, but is not language. Music says something, but not something separate from itself. It is not a system of signs. ${ }^{, 9}$

It is tempting to read Adorno's use of 'language' here simply as a metaphor for 'meaning'. Thus, music is as meaningful as language but in a different way, one that does not involve concepts or refer beyond itself in the manner of 'significative' language. This position is a rebuke to

\footnotetext{
${ }^{9}$ Adorno and Gillespie 1993, p. 401. The first part of this is a translation of a text titled 'Music and Language: A Fragment', an alternative translation of which is found in Adorno $1992 \mathrm{a}$.
} 
those who regard music purely as entertainment, 'more a matter of enjoyment than of culture', as Kant put it. ${ }^{10}$ But it does not differentiate itself from the well-worn idea of music as a means to 'articulate forms which language cannot set forth ${ }^{, 11}$ - the world of emotions, feelings, affect - a position which is often referred to as an 'aesthetics of expression'.

However, Adorno clearly believes that the relationship between music and language is not wholly metaphorical. Music is not entirely conceptless; it involves settled components (chords, cadences, etc.) which operate lexically in the manner of concepts and which demand interpretation. And while music's concepts are never brought together in an argument or decision, nevertheless its tendency to seem to say, 'This is the way it is', is a gesture of judgment which is in some way equivalent to language's ability to make assertions. ${ }^{12}$

But just as we are beginning to grasp the idea of music as a quasiconceptual but non-significative language, a medium for the communication of meanings of a particular type, Adorno undermines the analogy by insisting on the necessarily intentionless character of art's

\footnotetext{
${ }^{10}$ Kant 1987, p. 198.

11 Langer 1969, p. 233

12 Adorno and Gillespie 1993, p. 401.
} 
meaning. The mistake of the aesthetics of expression, he argues, is to regard music as a series of intended symbolic meanings residing in the content of the work. The coherence of the musical work operates differently from language: musical intentions are scattered and refracted rather than being harnessed in the manner of linguistic logic. The musical whole is realised by negating the intentions of the content, resulting in an overall intentionlessness. This does not amount to incoherence or sensuous immediacy, as the opposing view has it, because the musical work involves deliberate construction; but neither is it the kind of coherence that 'makes sense' in conventional terms. ${ }^{13}$ Nevertheless, for Adorno, this is where music's linguistic character lies: 'No art can be pinned down to what it says, and yet it speaks. ${ }^{14}$ Even modernist musical works which eschew meaning retain their similarity to language because 'they enunciate their meaninglessness with the same determinacy as traditional artworks enunciate their positive meaning'. ${ }^{15}$

It appears that a musical work's communicability paradoxically depends on its creators' conscious construction of it as a meaningful object while avoiding the attempt to speak through it in the manner of verbal language. As he states elsewhere, 'The more that art is thoroughly

\footnotetext{
${ }^{13}$ Adorno and Gillespie 1993, p. 404.

${ }_{14}^{14}$ Adorno and Gillespie 1993, p. 410.

${ }^{15}$ Adorno 1997, p. 201.
} 
organised as an object by the subject and divested of the subject's intentions, the more articulately does it speak according to the model of a nonconceptual, nonrigidified significative language'. ${ }^{16}$ This may help us make sense of the enigmatic closing remark of the 'Fragment': music's 'similarity to language is fulfilled as it distances itself from language'.17

But where, concretely within music, are its linguistic qualities to be found? The answer suggested by the 'Fragment' is in its form. Adorno identifies music's similarity to language in its 'objectivity', from which it derives its 'logic', ${ }^{18}$ and thus it is not inappropriate to understand him as meaning that the linguistic element of music derives from its constructed nature, that element that gives shape to a piece's specific content. The meaning of the first movement of Beethoven's Fifth Symphony is to be found not primarily in the famous opening four-note motif, but in the structure which unfolds from it. Indeed, that movement's meaning is only fully graspable within the context of all four movements of the symphony. As Adorno puts it in Aesthetic Theory, 'Through form, artworks gain their resemblance to language, seeming at every point to say just this and only this'. ${ }^{19}$ We might draw the conclusion that Adorno understands musical form to be governed by quasi-linguistic rules, and indeed, in the

\footnotetext{
${ }^{16}$ Adorno 1997, p. 87.

17 Adorno \& Gillespie 1993, p. 405.

${ }_{18}$ Adorno \& Gillespie 1993, p. 405-6.

19 Adorno 1997, p. 159.
} 
'Fragment' he refers to the 'musical grammar and syntax' which organises the content and gives it shape, as well as to the syntax of tonality. ${ }^{20}$

There appears to be a superficial resemblance between this idea and the theories of musical grammar spawned by Lerdahl and Jackendoff's 'generative theory' which was in turn inspired by Chomskean linguistics. ${ }^{21}$ However, Adorno's use of the term 'musical grammar' is much more allusive than the complex web of rules proposed by such theories. As Paddison points out, for Adorno, there is no rigid distinction to be made between form and content, ${ }^{22}$ the relationship between them is always dialectical because, as Adorno puts it, 'form can only be the form of a content'. ${ }^{23}$ That this suggests that there must also be linguistic elements to be found at the level of content is confirmed by Adorno's reference to the linguistic nature of musical themes, transitions, questions and answers, etc., independent of their context. ${ }^{24}$

One might be justified in wondering whether the distinction between form and content, a central but problematic one in Adorno's aesthetics, is

\footnotetext{
20 Adorno \& Gillespie 1993, p. 405.

21 Lerdahl and Jackendoff, 1983; Rebuschat 2012.

22 Paddison 1991.

23 Adorno 1992a, p. 405.

24 Adorno \& Gillespie 1993, p. 413.
} 
useful in relation to the question of art's linguistic character. This is particularly the case given that there are writings in which the distinction between form and content recedes and Adorno speaks more generically of the 'language of music', the 'language of art', 'Beethoven's symphonic language', and so on. ${ }^{25}$ This use of 'language' is interchangeable with Adorno's important concept of artistic or musical material, which he defines as 'the stuff with which the composer operates and in which he works ... the objectified and critically reflected state of the technical productive forces of an age with which any given composer is inevitably confronted'. Adorno comments that 'one might say that music operates within that language, rather than with it'. ${ }^{26}$

Things brings us to the conception of language that Adorno is using when he says that music is language-like. On the evidence of the 'Fragment' alone, it might be inferred that Adorno regards the nature of language as unproblematic. In identifying the ways in which music-aslanguage is different from 'significative' language, Adorno seems to operate within the dominant, positivist view of language as a stable, transparent system for the communication of ideas which exist independently of it. Thus, as we have seen, music speaks but, unlike

\footnotetext{
${ }^{25}$ Adorno 1997, pp. 160, 113, 185, 314.

${ }^{26}$ Adorno 1992b, p. 281.
} 
'significative' language, does not say 'something separate from itself'. ${ }^{27}$ Along the same lines, he makes the further distinction that while both language and music require interpretation, the form of interpretation is different in each case. For language, interpretation means understanding and results from a process of 'decoding'; whereas interpreting music is a mimetic rather than an analytic operation: it depends on playing or imitating it. ${ }^{28}$ In both examples, we find the notion that while music's meaning is immanent, verbal language conveys meanings which are in principle separable from itself. The 'Fragment' also refers to language as 'reified', suggesting a view of the stability and fixity of meanings which is echoed in Aesthetic Theory by a description of language as 'rigidified', and of words as 'imprisoned by a prestabilised universality'. ${ }^{29}$

The understanding of language evinced by these examples appears at odds with a Marxian one, and it is to the latter that we now turn.

\section{Voloshinov and a Marxist theory of language}

In the absence of a clear understanding of the nature of language itself, any theory of the language character of music will inevitably be

\footnotetext{
${ }^{27}$ Adorno \& Gillespie 1993, p. 401.

${ }^{28}$ Adorno \& Gillespie 1993, p. 403.

${ }^{29}$ Adorno 1997, pp. 87, 110.
} 
incomplete. It may also be contestable; for instance, an assertion that music follows linguistic-type rules of grammar and syntax depends on a view of languages as stable grammatical systems. A Marxist theory of language takes issue not only with this characterisation of language, but also, as Lecercle explains, with every one of the points which he identifies as comprising the dominant view of language in bourgeois society: immanence, functionality, transparency, ideality, systematicity and synchrony. ${ }^{30}$

The serious study of language from a Marxist perspective was begun by Valentin Voloshinov in the 1920s and in his hands becomes not only a theory of language but also a contribution to the materialist understanding of consciousness initiated by Marx and Engels in the famous passage on language in The German Ideology. ${ }^{31}$ Voloshinov's theory emerges by way of a challenge to two opposing positions in the field of linguistics which he refers to respectively as 'individual subjectivism' and 'abstract objectivism'. The former, whose principal exponent is Humboldt, is perhaps the dominant view in the nineteenth century and derives from Romanticism. It holds that language is composed of creative speech acts which are the product of individual psychology. Language is thus understood as analogous to artistic or

\footnotetext{
30 Lecercle 2009, pp. 67-72.

${ }^{31}$ Marx and Engels 1970, p. 51
} 
aesthetic creativity undertaken by individuals, its systematic aspect downplayed as merely a 'hardened crust' on the essentially creative and spontaneous nature of speech and writing. ${ }^{32}$

Abstract objectivism, by contrast, regards language as a system of phonetic, grammatical and lexical forms which are used by all speakers. This view tends to depict language as a stable, immutable, normative system which confronts speakers as ready-made. The most theoretically rigorous version of this view is that of Ferdinand de Saussure, for whom a strict distinction is to be made between language (langue) and utterance (parole). Only the former is the proper object for the study of linguistics since utterances are thoroughly individualistic and therefore resist classification, while langue is the social aspect and is to be understood as a closed system of arbitrary signs. ${ }^{33}$

Voloshinov argued that while both positions contained an element of truth, each was one-sided in its own way and neither was able to capture language correctly. Individual subjectivists sidelined the cultural aspect of language into which speakers are initiated and therefore could give no serious account of the collective nature of language or its relationship to society as a whole. Abstract objectivists could only deal with language

\footnotetext{
${ }^{32}$ Voloshinov 1973, p. 51.

${ }^{33}$ Voloshinov 1973, p. 57.
} 
by bracketing its actual use by speakers, consequently conceiving language as a static abstraction entirely separate from living practice. Both positions tended to idealism: on the one hand, language as the unique expression of individual consciousness; on the other, language as a quasi-Platonic form. And what neither position could account for was linguistic history or change: because for subjectivism there is no substrate of sufficient significance binding together individual speech acts to support a history; while objectivists conceive of language systems as essentially synchronous and ahistorical.

These twin positions have parallels in thinking about music, particularly Western art-music. Especially dominant in the nineteenth century, but also still influential, is the notion of great music as individual expression, the manifestation of a particular psyche, or genius, on the basis of which view what is focused upon and prioritised are the unique and original qualities of each individual work or compositional style. Sitting somewhat uneasily alongside this conception is a recognition of the systematic nature of musical language, which tends to be codified as a set of strict rules comprising the 'theory of music' or 'harmonic theory' to be passed on to successive generations of students and dehistoricised as somehow 'naturally' correct. 
Adorno's location of the language-like nature of music in the objective elements of form or musical material is relevant to this debate. As a conception of the historically determined and given nature of the elements that constitute the stuff of music in any period which every musician or composer has no choice but to confront, the initial thrust of Adorno's idea of artistic material is to counter overly individualistic notions of artistic creation with an emphasis on the cultural and socially imposed horizons within which artistic activity takes place. It allows him to declare that 'all music ... has an inalienable collective content: each single sound already says 'We'.,34 However, his concept of musical material is very far from an abstract, arbitrary, ahistorical system. On the contrary, Adorno's purpose in using it is to emphasise the historical nature of musical language and pointedly to debunk any pretensions to naturalness claimed for particular musical systems. Thus there is nothing fixed or stable about any musical system, Western tonality included, and musical material, although socially given for any generation, remains open in principle for revision through engagement by individual subjectivities. Indeed, Adorno's description of the more systematic and fixed aspect of 'material' - form - as the 'sedimentation' of the less fixed and more fluid aspects - content - is redolent of

${ }^{34}$ Adorno, 'Ideen zur Musiksoziologie' [1958], quoted in Paddison 1997, p. 115. 
Humboldt's view of the language-system as the hardened crust on individual creative expression.

For Adorno, this relationship between the individual (musical) subject and the existing state of musical language or material is also analogous to the relationship between individual and society. ${ }^{35}$ This debate about language, musical or otherwise, is, therefore, a version of the structure/agency dichotomy which is rehearsed regularly in social theory, its Marxist variant included. The individual subjectivist position rests on methodological individualism and essentially conforms to liberal myths about the nature of free individuals in an open, pluralistic society. Abstract objectivism, especially in its Saussurean form, is most akin to Althusserian structuralism in its description of the construction of subjectivity by social institutions and cultural norms. Although Althusser, unlike Saussure, retains a concept of history, it is, famously, one 'without a subject', which has a similar effect of marginalising the role of agency in historical change. ${ }^{36}$

Adorno's conception of how the relationship between individual and society is embodied within music and art represents an important intervention in that debate which seeks, like Voloshinov, to avoid the

\footnotetext{
${ }^{35}$ He draws this analogy explicitly in 'Little Heresy' [1965], Leppert 2002, p. 320.

${ }^{36}$ See Callinicos 2004 and Althusser 1996.
} 
pitfalls of both extreme subjectivism and objectivism. There are places in his writings, however, where, in his determination to challenge the emphasis on individual creativity and inspiration which dominate discussions of, especially 'classical', music, Adorno comes close to suggesting that music composes itself. He writes of the 'composition wait[ing] to be released' from the piano keys, describing the individual responsible for the work of art as 'scarcely more than a limiting value, something minimal required by the artwork for its crystallisation'. ${ }^{37}$ For Voloshinov, language is a 'social edifice of ideological signs' of which the individual is not the architect. But although consciousness takes shape within this semiotic material, he describes individual consciousness as 'nurtured on signs', rather than structured or determined by them. ${ }^{38}$ Unlike our encounters with a foreign language, our native language is not handed-down to us as a ready-made system. Language as a 'system' is an abstraction which does not exist for ordinary speakers. Rather, an individual's consciousness takes shape as a result of entering the intersubjective stream of language from where it also has the power in turn to shape language. ${ }^{39}$ Adorno's theorisation of musical language lacks Voloshinov's awareness that social structures not only serve to limit the possibilities for human agency, but enable it in crucial

\footnotetext{
${ }^{37}$ Adorno 1997, pp. 219, 220

${ }^{38}$ Voloshinov 1973, p. 13.

${ }^{39}$ Voloshinov 1973, p. 81.
} 
ways. His scepticism about Marx's identification of the proletariat as the gravediggers of capitalism by virtue of that class's structural position in society is an aspect of the same failing. It leads him to argue, famously, that the encroachment of the power of the culture industry over artistic language, as an aspect of the progressive domination of capitalism's instrumental reason over society at large, threatens to extinguish, or worse, to coopt, subjectivity through its reified structures. Historically bequeathed musical language, on this account, as what was once subjective turned objective and rigid, is not so much enabling or nurturing of agency as a mortal threat to it. Nevertheless, Adorno insists on the ability of individual subjectivity to maintain itself in the face of these forces, albeit a rather specialised, aesthetic subjectivity which is somewhat distant from Voloshinov's 'everyday' consciousness.

\section{Music as consciousness?}

Despite the shared concerns in their respective theories regarding the interpenetration of individual and social, subjective and objective, Voloshinov's theory of language aims to ground a materialist understanding of consciousness in a way that is somewhat alien to Adorno's thinking. For Voloshinov, consciousness, although a property of each individual, is ultimately social by virtue of the social nature of its medium - the world of ideological signs, the most important of which is 
language. Is it realistic to think of music, on the basis of its social character, as another medium of consciousness? On the face of it, that seems far-fetched. Music, at least in its autonomous form, does not have what, for Voloshinov, is the chief element of the sign-world, the word, which, although polysemantic in Voloshinov's view, does not splinter into as many words as it has contextual meanings, but is held together by the factor which is common to them. ${ }^{40}$ Even music's most 'lexical' elements - think of a dominant seventh chord - lack that degree of unity of meaning across all the contexts in which they are found, from, say, Haydn's 'Toy' Symphony to Mingus's 'Goodbye Pork Pie Hat'. This makes it difficult to think of music as a 'sign-system' and explains why it is conventionally described as expressive rather than referential or discursive, at most connotative rather than denotative. ${ }^{41}$

Voloshinov, however, is prepared to consider musical sounds, along with drawing, colours, etc., part of the material of consciousness. ${ }^{42}$ His motivation for doing so has something to do with his critique of the transparency of language, which depends in turn on the particular characteristics of the concept of the sign within his theory. Central to this

\footnotetext{
${ }^{40}$ Voloshinov 1973, p. 80.

${ }^{41}$ Raymond Williams argues that despite Voloshinov's insights, there are problems with the concept of 'sign-system' even when applied to language. Williams 1977, p. 42.

${ }^{42}$ Voloshinov 1973, p. 90.
} 
is the distinction he makes between sign and signal. ${ }^{43} \mathrm{~A}$ signal is a phonological, pictorial or sonic unit which has a fixed and distinct relationship to its referent and functions by way of its being recognised by its receiver. Signs, by contrast, are 'multi-accentual' and operate very differently:

The constituent factor for the linguistic form, as for the sign, is not at all its self-identity as signal but its specific variability; and the constituent factor for understanding the linguistic form is not recognition of "the same thing", but understanding the proper sense of the word, i.e., orientation in the particular, given context and in the particular, given situation - orientation in the dynamic process of becoming and not "orientation" in some inert state. ${ }^{44}$

The meaning of words can never be limited to their dictionary definition; they are thoroughly historical, carrying all the sedimented meanings of their previous use, and are always open to further inflection as a result of their further use in concrete utterances. That is why understanding is an active, dialogic process, rather than a passive one of decoding fixed meanings. Furthermore, language as a material phenomenon cannot be

\footnotetext{
${ }^{43}$ Williams 1977, p. 38.

${ }^{44}$ Voloshinov 1973, p. 69.
} 
separated from the world, and thus refracts it, rather than simply reflecting it, as mechanical materialist theories would have it. ${ }^{45}$

All of this implies a rejection of one of the central elements of the generally accepted conception of language: the idea that language is 'transparent', that it is a means for expressing ideas which are separate from it. Voloshinov rejects the dualism of theories of expression which posit the existence of an inner, psychic phenomenon distinct from its outer manifestation. There can be no such thing as experience independent of its embodiment in signs, he argues, and therefore, 'it is not experience that organises expression, but the other way around expression organises experience. ${ }^{46}$ It follows that we must understand language, even when at its most referential, as opaque, rather than transparent. As Lecercle puts it, 'language never makes itself invisible ... we say what our language allows us to say'. ${ }^{47}$

If this is true, language is less distinct from music than is generally presumed, in spite of its referentiality. Music, with its minimal referential content, is perhaps the most opaque of all 'ideological sign-systems', to use Voloshinov's terminology. Adorno, as we have seen, rejects the

\footnotetext{
${ }^{45}$ Voloshinov 1973, pp. 10, 19, 23; Lecercle 2009, p. 110; Williams 1977, pp. 33-4.

${ }^{46}$ Voloshinov 1973, p. 85.

${ }^{47}$ Lecercle 2009, p. 71.
} 
‘aesthetics of expression' (although the grounds he gives are different from Voloshinov's), but he also opposes the formalism of Hanslick for whom music's 'sounding forms' refer to nothing beyond themselves. ${ }^{48}$ Unlike post-structuralists whose rejection of subjectivity tends towards the notion of language speaking itself, ${ }^{49}$ he is committed to the idea that music is a means of cognition, albeit a veiled one,${ }^{50}$ but what is being said if meaningful language - musical or verbal - is neither transparent nor purely self-referential?

Voloshinov's answer is that the meaning of linguistic utterances is rooted in the dialogic, inter-subjective relationships between individuals in the context of their material existence. Language is the material of consciousness, and, as Marx and Engels put it, 'Consciousness can never be anything else than conscious existence, and the existence of men is their actual life-process. ${ }^{.51}$ Might we say that the content of music is essentially the same, that music is also a 'semiotic material of inner life - of consciousness', through which we grasp our relations with the others and the world $?^{52}$ The difficulty with that suggestion is not that the content of music is ineffable, as Raffman would have it. ${ }^{53}$ She is

\footnotetext{
${ }^{48}$ Hanslick 1957, p. 48.

${ }^{49}$ Bowie 1989.

50 Adorno \& Gillespie 1993, p. 405.

${ }^{51}$ Marx and Engels 1970, p. 47.

52 Voloshinov 1973, p. 14

${ }^{53}$ Raffman 1993, pp. 2-10.
} 
mistaking ineffability for untranslatability into another medium. Rather, it is that language has its basis in a spontaneous, dialogic form to which all members of society (or, more specifically, a particular language-group) have more or less equal access. The word holds this pre-eminent position due to the fact that, as Voloshinov points out, it 'is produced by the individual organism's own means without recourse to any equipment or any other kind of extracorporeal material', and its material is 'pliable and expressible by bodily means'. ${ }^{54}$ This contrasts somewhat with the nature and scope of music-making in our society, which tends to be increasingly technology-dependent and monopolised by trained specialists.

Nonetheless, it is at least arguable that, notwithstanding the unevenness of access to it, musicality comprises an element of consciousness, understood, following Voloshinov, as simultaneously individual and social. Musical 'utterances' carry their sedimented history like words do and require an active process of understanding even where it is not possible for those hearing them to respond with an utterance of their own. This at least would provide a way of conceiving the content of musical meaning positively without resorting to either the aesthetics of expression or formalism. I have attempted elsewhere to theorise how

\footnotetext{
${ }^{54}$ Voloshinov 1973, p. 14. See Chik Collins's emphasis of this point in his argument with David McNally in Collins 2004, p. 180-1
} 
music can articulate an aspect of consciousness along these lines. ${ }^{55}$ Meanwhile, ethnomusicologists have provided accounts of very many societies in which music, or 'something like music', has been a much more generally shared ideological currency than it is in our own. ${ }^{56}$ Of course, from an Adornian perspective, such manifestations of music predate its emergence as an autonomous form of aesthetic expression, at a time when it was still enmeshed in, and subordinate to, a variety of ideological social practices, mostly of a religious nature. Further, the claim that the depth and complexity of musical expression achieved during its autonomous phase has depended on sacrificing spontaneity in favour of literariness is irrefutable. However, the historical existence of societies with a more equal and generalised participation in musical life at least lends credence to the possibility that in a future society music might take on something of the dialogic quality currently restricted to language, and consequently play a more central role in mediating consciousness.

\section{Adorno's philosophy of language}

If the 'Fragment' evinces a conception of language which appears to be insufficiently critical of the dominant view, there are others of Adorno's

\footnotetext{
${ }^{55} \mathrm{xxxxxx}$

${ }^{56}$ Cross 2012. Cross's examples are from Native American, Australian Aboriginal, African, Amazonian and Papuan societies.
} 
writings which articulate a position much closer to the Marxist one initiated by Voloshinov, particularly on the crucial questions of language's non-transparency and its contextual dependency. In his 'Theses on the Language of the Philosopher', Adorno denounces structuralist and idealist conceptions of language which hold both that words' relationship to objects and concepts is arbitrary, 'held together solely by consciousness', and that words can always be adequate to reality. In what might be read as a defence of his own somewhat elliptical style of writing, Adorno rejects the demand of easily understandable, universally communicable philosophical language as either naïvely banal or an intentional apologia for the status quo. Rather, in terms which are not far from those of Voloshinov, 'words are never merely signs of what is thought under them, but rather history erupts into words, establishing their truth-character ... history and truth meet in the word. ${ }^{57}$ Voloshinov would add that the multi-accentual character of words makes them not merely historical, but also an arena of class struggle, the ruling class constantly striving to suppress the critical judgments immanent in the 'illegitimate' use of words by cementing their meanings and making them 'uniaccentual'. ${ }^{58}$

\footnotetext{
${ }^{57}$ Adorno 2007, p. 35-6.

${ }^{58}$ Voloshinov 1973, p. 23. McNally makes much of this point in his discussion of Voloshinov in McNally 2001, p. 116. Contemporary ruling class strategy is not simply to fix the meanings of words but to imbue them through usage with a normative valency, e.g. 'refugee', 'Muslim', etc.
} 
Crucially for the issue of the similarity between music and language, Adorno contradicts the implicit position expressed in the 'Fragment' and asserts that philosophical thoughts do not exist independently of the words used to convey them. ${ }^{59}$ Throughout this text, Adorno seeks to restrict his comments to 'philosophical' language only, arguing in the same vein that philosophical ideas may be contradicted or betrayed by the language chosen to express them. Indeed, elsewhere, Marx comes in for criticism on this score. ${ }^{60}$ This restriction reflects Adorno's belief that in the era of the culture industry only the rarified domains of philosophy and art remain available for serious attempts to grapple with the truth of the world; but since even the most banal and everyday of utterances address the reality of lived existence in some way, his argument seems applicable to all language to some degree.

That Adorno accepts the importance of context in determining the meaning of words in general is indicated by the example in 'The Essay as Form' of the émigré who

is obliged, in a foreign country, to speak that country's language instead of patching it together from its elements, as he did in

\footnotetext{
${ }^{59}$ Adorno 2007, p. 35-6.

60 'The linguistic manner of Marx has long since been suspicious to me. ... For example the derivative rhetoric and use of metaphor-does this not bear witness against him, from the perspective of the philosophy of history?' Frankfurter Adorno Blätter 6 cited in Müller 2009, p. 85.
} 
school. He will read without a dictionary. If he has [come across] the same word thirty times, in constantly changing contexts, he has a clearer grasp of it than he would if he looked up all the word's meanings; meanings that are generally too narrow, considering they change depending on the context, and too vague in view of the nuances that the context establishes in every individual case. ${ }^{61}$

This looks very much like 'multi-accentuality', and we encounter a similar comparison about foreign languages in Voloshinov with the assertion that dictionary definitions implying univocal meanings of words are a poor substitute for learning a language immersively, precisely because of the multi-accentual and context-dependent nature of linguistic meaning. In addition, the process of attempting to speak a foreign language demonstrates clearly that we think in and with language, rather than in 'pure' thought, and that we only succeed in speaking another language fluently when our thoughts are not first taking shape in our mother tongue. This view that language is not the neutral purveyor of ideas beyond itself ${ }^{62}$ leads Adorno to conclude that, just as musical critique is at least partly musicological, philosophical critique may take the form of a critique of the language of philosophy.

\footnotetext{
${ }^{61}$ Adorno 1984, p. 161.

62 Gandesha 2006, p. 149.
} 
Typically, given his artistic predilections, Adorno has a modernist perspective on the situation facing what we might call the 'serious user of language'. Like the language of music and art, verbal language is in a ruined and disintegrated state. A fractured society has destroyed its universality while the forces of reification - positivist philosophy and science - have, by asserting stable correspondences between words and things, emptied it of truth. Voloshinov also detects a similar reification of the word in written discourse, which he attributes to the growing reluctance of authors to make declaratory statements in literature, philosophy and the humanities in favour of presenting the opinions of others at second-hand. Confident that circumstances, not least the class struggle, will always impel language-users to find new ways of inflecting the meaning of words to make them adequate to their situation and purpose, he looks to the proletariat for the rejuvenation of the literary word, 'the word that really means and takes responsibility for what it says'. ${ }^{63}$ Adorno has no such confidence; he believes it falls to critical thinkers, philosophers, to wrest words out of the context in which they are presented to us, recontextualising and reconfiguring them for new uses. The insertion of foreign words into a text is one way of upsetting the 'customary ring of naturalness' which inheres in

${ }^{63}$ Voloshinov 1973, p. 159. 
language ${ }^{64}$ We should ask, he says, not whether words are adequate to objects, but whether they are capable of bearing the intentions demanded of them. In other words, it is necessary to adopt aesthetic rather than logical criteria of judgment, and to focus on what he calls 'the aesthetic dignity of words'. ${ }^{65}$ That this dignity depends at least in part on a mimetic relationship between words and things is indicated by his comment elsewhere that 'truth is not adaequatio, but affinity'. ${ }^{66}$

It is noticeable that, compared to the discussion of language in the 'Fragment', the adjective 'significative' has been dropped, as has the possibility of distinguishing language from music by its referentiality, transparency and its requirement to be 'decoded'. It is unclear whether Adorno intends the theory of language set out in the 'Theses' as a general one or to have arisen with a particular historical conjuncture, the high-modernist moment. In any case, we might choose to short-circuit that question by extending to language Bürger's theory of the avantgarde, which holds that it is only from the perspective of the crisis manifested by the challenge of the modernist movements of the early twentieth century that the true nature of bourgeois art and culture

\footnotetext{
${ }^{64}$ Adorno, Notes to Literature, cited in Gandesha 2006, p. 157.

${ }^{65}$ Adorno 2007, pp. 37-8.

${ }^{66}$ Adorno 1993, p. 41.
} 
becomes visible. ${ }^{67}$ As Jacqueline Rose puts it, "up until that point, it was possible to see language as immune to social and political contradictions, lord of all it surveyed, blind to the role it plays in shaping a world it claimed merely, and innocently, to represent'. ${ }^{68}$

A similar modernist perspective on art and language is pursued in Adorno’s late essay ‘On Some Relationships Between Music and Painting'. In what appears to be a refinement of the statement in the 'Fragment' that music becomes more like language the more it distances itself from language, Adorno asserts here that music and painting show more affinity to language the less they model themselves on communication. Adorno again appears to be making a distinction between language-as-communication and language-as-knowledge, between everyday speech and 'serious' writing, or what he refers to in this essay as écriture. He writes, 'music and painting become writing through their renunciation of the communicative, which is precisely the element, in both media, that is in truth unlinguistic, because it suggests what is merely subjectively desired. ${ }^{69}$ Here again, spoken, lived language finds itself severed from the spectrum of language forms and impugned by Adorno for its supposed egoism and pragmatism. This is

\footnotetext{
67 Bürger 1984.

68 Rose 2016, p. 11.

${ }^{69}$ Adorno 1995, pp. 71-2.
} 
hard to reconcile with his commitment elsewhere to an irremediably intersubjective conception of even the most subjective of locutions, ${ }^{70}$ and the central tenet of materialism that ideas are always unavoidably tied to practice.

The argument of 'On Some Relationships' is that abstract visual art is becoming more like écriture, and closer also to music, as it relinquishes its referential element and concentrates its constructed element. But Adorno also argues that in modernist art, there is a further convergence of painting and music caused by the emergence of an expressive element which has broken away from what it might have expressed and become 'pure' expression. Paradoxically, Adorno identifies this expressive or mimetic component with art's writing or linguistic character. Despite the increasing presence of rationality in artworks, art, claims Adorno, cannot do without an element of its antithesis expression - which seismographically registers the reverberations of the original mimetic impulse at the root of all art. Now he argues that in modernist art as écriture, art is reaching a point where it may be able to abandon itself completely to mimesis once again, because the

\footnotetext{
${ }^{70}$ For example, his discussion of Husserl's 'l' in Adorno 1982, p. 230.
} 
heterogeneity of its material, its implicatedness with the empirical world, has been overcome. ${ }^{71}$

This idea is also present in Aesthetic Theory, where he writes, 'everything in artworks that resembles language originates in form and is thus transformed into the antithesis of form, the mimetic impulse'. ${ }^{72}$ The thought is that the dialectical relationship between form and content, rationality and mimesis, results, in the most progressive of abstract art, in the increasing possibility of working directly with naked material without an intermediate layer of idiom or representation. This would be a recuperation, at a higher level, of the ancient, undivided state of 'art', before it became a separate sphere of activity. ${ }^{73}$ Adorno suggests that music is already at this stage because of its minimally referential character, but it is questionable whether musical idiom can be relinquished as easily as can representation in visual art. Those composers championed by Adorno for breaking with tonality and its forms found themselves needing to invent systems such as serialism to replace some of its functions. The argument is similar to that made in 'Vers une musique informelle' where Adorno looks forward to the possibility of a music without any imposed structure, or where the raw

\footnotetext{
${ }_{71}^{71}$ Adorno 1995, pp. 72-3.

72 Adorno 1997, p. 190.

73 Adorno 1995, pp. 77-8.
} 
content alone is allowed to determine the shape of the whole. ${ }^{74}$ That he sees this as akin to writing, or at least a certain kind of writing, is demonstrated by its affinity to his argument in 'The Essay as Form', which proposes a form of writing which 'erects no scaffolding, no edifice', and whose individual elements are not arranged from the perspective of an overall argument, a terminus ad quo or punchline,$^{75}$ but rather are 'equidistant from the centre' in the manner of Schoenberg's twelve-tone music. $^{76}$

Despite the dialectical reversal that has taken place in which the language-like nature of music initially associated with form ends up appearing most clearly where composition is most 'unformed', there is a continuity at the heart of Adorno's position. It is that an artwork's language character lies in its constructedness, its wholeness, its objectivity. This is the nature of the artwork which he describes in Aesthetic Theory as a 'windowless monad' ${ }^{77}$ It is that characteristic by which the artwork distances itself from social existence, claims aesthetic status and says something about the world, as opposed to simply being part of it.

\footnotetext{
${ }^{74}$ Adorno 1992b.

${ }^{75}$ Adorno 1984, p. 161.

${ }_{77}^{76}$ Adorno, 'Neunzehn Beiträge über neue Musik', cited in Paddison 1997, p. 177.

${ }^{77}$ Adorno 1997, p. 6.
} 
This highlights another difficulty in comparing music with language.

Language, as discussed by Voloshinov, is not restricted to the aesthetic realm, but is interwoven with the fabric of material life. The vast majority of it is not constructed, honed, shaped in the manner of an artwork, or even written, but is a spontaneous and transient part of everyday existence. Voloshinov recognises the existence of written forms of language but does not attribute a qualitative difference to them. A book, he suggests, should, like any utterance, be considered part of a dialogue, 'a verbal performance in print'. It does not stand isolated and aloof from other speech but engages in a wider linguistic exchange by responding to previous literature and provoking future responses in the form of reviews and discussion, which may be written or spoken. The printed, or, we might add, composed, verbal performance 'engages ... in ideological colloquy of large scale: it responds to something, objects to something, affirms something, anticipates possible responses and objections, seeks support, and so on. ${ }^{18}$

If this is a productive way to conceive of literary works of art, then it might also be a way of understanding musical works. The virtue of thinking about music as a kind of language is that it encourages us to

\footnotetext{
${ }^{78}$ This is the central idea of Bakhtin's concept of dialogism, although it is important to note that its use here is limited to a dialogue between texts, rather than the idea of a dialogue between voices, registers and languages within a text, or heteroglossia, which postmodern cultural theorists find so attractive. For a brief overview of the latter in relation to music, see Cook 2003, p. 210.
} 
regard individual works as instantiations of a cultural medium, which both enables and constrains them. Musical pieces are 'utterances', contributions to, and interventions in, the ongoing musical discourse of society. On the other hand, to fail to make a distinction between the pragmatic function of language and its aesthetic forms such as poetry is to miss something important. Adorno's attempt to divide philosophical from 'ordinary' language may be unsustainable, and he is too quick to look to the aesthetic realm for salvation from the positivist degradation of words, but Voloshinov appears blind to the mimetic element that separates artistic from exclusively denotative language. It is a similar mistake to that made by Cross when he suggests that models of the social utility of music in non-Western societies can be extended to all music. $^{79}$

More challenging perhaps, is reconciling music with the question of consciousness which is central to Voloshinov's account of language. Crucial to this is the concept of inner speech. Voloshinov contends that without language, individual psychic life remains inchoate and animalistic. It is the word which structures inner feelings into experience, ensuring in the process that consciousness is at once social and individual. Experience necessarily takes the initial form of inner speech,

${ }^{79}$ Cross 2012, p. 324. 
whose subsequent outward expression makes it more distinct and definite. $^{80}$

Voloshinov regards the word as the ideological phenomenon par excellence', the 'essential ingredient for all ideological creativity whatever'. He argues that,

The process of understanding any ideological phenomenon at all (be it a picture, a piece of music, a ritual, or an act of human conduct) cannot operate without the participation of inner speech. All manifestations of ideological creativity - all other nonverbal signs - are bathed by, suspended in, and cannot be entirely segregated or divorced from the element of speech.

He admits that words cannot replace other kinds of ideological sign, that they cannot adequately convey a musical composition or a pictorial image. But he insists that all other ideological signs 'have support in and are accompanied by words, just as is the case with singing and its musical accompaniment'. ${ }^{81}$

\footnotetext{
${ }^{80}$ Voloshinov 1973, pp. 35-9, 87.

${ }^{81}$ Voloshinov 1973, p. 15.
} 
It is useful that Voloshinov recognises the existence of non-verbal signs and ideological systems, but his insistence on the presence of the word in all ideological phenomena is misplaced. If it is plausible to understand musical language dialogically, and if musical meaning cannot be translated into words, then it follows that there must be a musical equivalent to inner speech, marginal to consciousness compared to words, certainly, but necessary as the link between individuals and their shared musical culture.

Such an 'inner musical speech' does indeed exist. The phenomenon of 'earworms', bits of tunes or songs which replay endlessly in one's mind, which has received academic attention recently, is an instance of 'mental musical imagery' that most people will have experienced. ${ }^{82}$ Much of the literature concentrates on the unwanted nature of this phenomenon, the problem of not being able to dislodge from one's mind the catchy chorus of a pop song, whose presence as a 'hook' has been designed to serve the commercial interests of the music industry by persisting in this way. But such mental musical phenomena need not be unwelcome. Experiences have a way of resonating in our minds, the more so the more powerful they are, so it is normal to 'hear' elements of music we have experienced played back in our mind's ear long after the

${ }^{82}$ e.g. Williamson and Jilka 2014, pp. 653-670. 
performance has finished. However, Toynbee argues that for most people this experience is only minimally dialogic: those who have little or no practical engagement with music beyond casual whistling or singing in the shower have little opportunity to contribute further to musical discourse. ${ }^{83}$

On the other hand, the degree of development of musical inner speech is much higher for those involved in musical activity, and probably highest of all for full-time and trained musicians, especially those who compose or create music. ${ }^{84}$ Just as with language or any other ideological form ${ }^{85}$ creative musical ideas do not emerge from a mystical process of inspiration, but are the result of a practical and mental engagement with existing musical culture, or musical language. The fact that music comes nowhere near the universal and essential role that language plays in social life does not necessarily mean either that it requires the support of language or that the way its inner speech operates is fundamentally different. Although all individuals participate in outer, and therefore also inner, verbal speech, they do so at different levels: those who write seriously or are required to speak coherently in

\footnotetext{
83 Toynbee 2003, p. 105.

84 Studies confirm that there is a link between degree of musical activity and training and levels of musical imagery experienced: Liikkanen 2012, pp. 236-256; Bailes 2007, pp. 555-570.

${ }^{85}$ I am adopting Voloshinov's neutral use of the word 'ideological' here, aware that it deviates from the more normative sense that it also has in the Marxian tradition, including in Adorno, because the alternatives - artistic medium, means of expression, etc. - all suggest the separation of form and content, the what is said from the how, that we have discarded as erroneous.
} 
public will have a more well-developed inner speech. As Voloshinov puts it, what is commonly called 'creative individuality' is inner speech whose outward expression has attained a 'high social polish' ${ }^{86}$ The fact that musical engagement remains limited for many in our society means only that the distribution of well-developed musical inner speech is more uneven across society than is the case for verbal language.

\section{Conclusion}

How does a study of the relationship between the ideas of Adorno and Voloshinov contribute to a historical materialist understanding of music? First, against a trend continuously fueled by commercial forces that presents it as mere entertainment or diversion, Adorno's description of music as language-like asserts the meaningfulness of music, its ability to 'say' something, something which cannot be said in another way and which without music would go unsaid.

Second, to the extent that Adorno's notion of the 'language of music' is coterminous with his concept of 'musical material' (and as we have seen, it both is and is not), it encourages a rejection of an individualistic and subjectivistic view of musical creativity by insisting on the historically and socially determined nature of the very stuff with which every

86 Voloshinov 1973, p. 93. 
musically-active individual is confronted and must engage. Second to insisting that music is 'agitated layers of air' generated by physical bodies acting on the material world, this insight is the foundation stone of a materialist understanding of music.

However, if this approach of Adorno's helps us to avoid subjectivism, Voloshinov's theory of language can rescue us from the opposite error, an overemphasis on music as an abstract, stable system. Through a critique of Saussurean linguistics, it can be shown by analogy that, despite its codification in textbooks of theory and harmony, and the existence of complex theories of musical grammar and syntax, musical language is not an abstract system. It exists only in and through actual pieces of music, its meaning constantly open to revision and renegotiation by its listeners, its elements mutating as a result of the continuous engagement of performers and composers within the context of social life as a whole. In principle, Adorno and Voloshinov are fundamentally agreed on this anti-objectivist position, although the latter may provide a way of showing that the former's permanent fear that musical language is solidifying into a fully-reified synchronous system homologous with an unfree society is unwarranted. 
Voloshinov's Marxist approach to language also clarifies the issue of transparency, commonly held to be the source of the fundamental difference between music and verbal language. His insistence on the context-dependent and unfixed nature of linguistic meaning combined with his critique of 'expressionism' - the idea that thoughts are prior to, or separate from, the words used to convey them - reveals words, contrary to established commonsense, to share, in an important way, music's inability to say anything beyond itself. We grasp the world and our mental activity through language, we don't put our thoughts and feelings into words. This insight affects an understanding of musical meaning by qualifying the notions of 'expression' and 'communication' commonly applied to music. If by those terms is meant the expression or communication of ideas, thoughts, stories or feelings which can be captured by verbal language or by other means, music is neither expressive nor communicative. On its own it cannot tell a story or express claustrophobia or convey a political idea like Czech nationalism because these are all phenomena that have been grasped through verbal language. On the other hand, the claim that music cannot say anything beyond itself does not imply that music is effectively meaningless. Declaring music to be language-like is to say that it is an ideological means by which individuals grasp and make conscious for themselves and for each other aspects of their material existence. That 
is the sense in which music might be said to be both expressive and communicative: expressive because it says something, even if that something cannot be translated into another 'language'; communicative because, like language, it is a bridge between speaker and listener, ${ }^{87}$ and 'only because it exists for others does it exist for me too' ${ }^{88}$

Finally, this brings us to the issue of the dialogic nature of music and the existence of 'inner musical speech'. Aside from any Bakhtinian heteroglossia they may display, musical works are dialogic in the more straightforward way that Voloshinov claims literary works are. They are not monads which stand as isolated monuments; each is part of an ongoing social musical dialogue.

But I suggest that their dialogic nature goes deeper, extending to every individual. The origins of music lie in exactly the same pliable material producible by the human body as speech. Indeed, speech itself is musical to the extent that it depends on pitch (intonation), rhythm and accent. Toynbee overstates the extent to which the majority are excluded from active musical participation in modern societies in a way that precludes a fully dialogic conception of music. Everyone sings, it is just that social norms inhibit many from regarding this as a properly

\footnotetext{
${ }^{87}$ Voloshinov 1973, p. 86.

${ }^{88}$ Paraphrasing Marx and Engels 1970, p. 51
} 
musical activity. Moreover, recent data shows that more than ten percent of adults in the USA and in Britain regularly play an instrument, and the fact that the figure for schoolchildren is more than twice that indicates that a much higher proportion have experience of doing so. ${ }^{89}$ These figures do not include those who belong to choirs or take part in other organised singing, of which there are a great many more. Those who engage in karaoke might be considered another layer, and beyond these are a very large number whose engagement with music involves dancing to it, formally or informally. Some of these are people who participate in the social phenomenon of 'musical language' at a level which exceeds the mimetic interpretation of existing music that Adorno thought necessary for understanding, and includes producing new 'utterances' by composing, jamming or improvising. In fact, an important phenomenon in the Western music of the last century has been the emergence of popular forms which rely on a much more dialogic process for their creation than either the composed model of Western art-music or the handed-down model of traditional folk-forms. But even those individuals whose activity is limited to choosing what to load onto their iPod should be regarded as having some degree of dialogic involvement with music since they demonstrate the process of active understanding which Voloshinov argued was demanded by sign-systems.

${ }^{89}$ Statista Research Analysis 2014. 
In other words, there are very good reasons for regarding music in Voloshinovian terms as an ideological sign system which is as extensive, if not as universally well-developed, as verbal language. Clearly, words are the primary means by which we grasp our existence and our relationship with the world and with each other. But if music involves an equivalent relationship between individual and society, between utterance and structure, if it circulates socially in the manner of a language, if it also 'speaks', saying something about our existence, then there must be components of consciousness, taking the form of inner musical speech, which correspond to it. This is perhaps what Voloshinov's contemporary in 1920s Russia, Anatoly Lunacharsky, at that time People's Commissar for Education in the post-revolutionary government, was referring to when he wrote,

I would say that we do not even need music that simply satisfies the wants of the masses, but music founded on what is heard in the unique rhythms of these masses, in the unique musical consciousness they carry with them. ${ }^{90}$

${ }^{90}$ Quoted in Nelson 2004, p. 67. 
Leaving for another discussion the ways in which such consciousness might differ between social classes, if music is a way of 'refracting' our world semiotically, then consciousness is partly musical too. This, in the last analysis, is what musical meaning consists in.

It is generally accepted that an active engagement with the arts is an enriching experience, both for the individual and for society as a whole. The Marxist version of this position derives from the notion, expressed by the young Marx, that the development of human senses - 'a musical ear, an eye for beauty of form' - is an affirmation of our humanity and an end in itself. ${ }^{91}$ Following the line our argument has taken, we can reformulate what is positive in such development as the ability to participate more fully in all the human languages of the senses, music included. The political corollary of this is the demand for a society in which musical culture is not dominated by the commodified products of a specialist caste of makers, but which provides conditions which permit the fullest possible engagement by all in the social language of music.

\section{References}

Abel, Mark 2014, Groove: An Aesthetic of Measured Time, Leiden: Brill.

\footnotetext{
${ }^{91}$ Marx, K. Economic and Philosophical Manuscripts (1844) in Baxandall, L. and S. Morawski (eds.), Marx Engels on Literature and Art (Documents on Marxist Aesthetics I), New York: International General, 1973. p. 52
} 
Adorno, Theodor W. 1982, Against Epistemology: A Metacritique; Studies in Husserl and the Phenomenological Antinomies, tr. W. Domingo, Oxford: Blackwell.

Adorno, Theodor W. 1984, 'The Essay as Form', New German Critique, No. 32, pp. 151-71

Adorno, Theodor W. 1992a, 'Music and Language: A Fragment' in Theodor W. Adorno, Quasi una Fantasia: Essays on Modern Music, London: Verso.

Adorno, Theodor W. 1992b, 'Vers une musique informelle', in Theodor W. Adorno, Quasi una Fantasia: Essays on Modern Music, London: Verso.

Adorno, Theodor W. 1993, Hegel: Three Studies, Cambridge, Mass: MIT Press.

Adorno, Theodor W. 1995 [1964], 'On Some Relationships Between Music and Painting', Musical Quarterly 79/1, pp. 66-79

Adorno, Theodor W. 1997, Aesthetic Theory, London: Continuum.

Adorno, Theodor W. 2007, 'Theses on the Language of the Philosopher' in Adorno and the Need in Thinking: New Critical Essays, edited by Donald A. Burke et al, University of Toronto Press.

Adorno, Theodor W. and Susan Gillespie 1993, 'Music, Language, Composition', The Musical Quarterly, Vol. 77, No. 3, pp. 401-14

Althusser, Louis 1996, For Marx, London: Verso.

Bailes, Freya 2007, 'The prevalence and nature of imagined music in the everyday lives of music students', Psychology of Music, 35(4), pp. 55570

Benjamin, Walter 1993, 'On Language as Such and on the Language of Man', in Walter Benjamin, Selected Writings, Volume 1, 1913-1926, Cambridge, Mass: Harvard University Press.

Bowie, Andrew 1989, 'Music, Language and Modernity' in The Problems of Modernity: Adorno and Benjamin, edited by Andrew Benjamin, London: Routledge.

Bürger, Peter 1984, Theory of the Avant-Garde, Minneapolis, University of Minnesota Press. 
Callinicos, Alex 2004, Making History: Agency, Structure, and Change in Social Theory, Leiden: Brill.

Collins, Chik 2004, 'Marxism and Language: A Response to McNally', in Historical Materialism 12 (2), pp. 169-87.

Cook, Nicholas 2003, 'Music as Performance', in The Cultural Study of Music: a critical introduction, edited by Martin Clayton et al, London: Routledge.

Cooke, Deryck 1959, The Language of Music

Cross, lan 2012, 'Music as a social and cognitive process', in Language and Music as Cognitive Systems, edited by Patrick Rebuschat et al, Oxford University Press.

Engels, Frederick 1934 [1876], The Part Played by Labour in the Transition from Ape to Man, Moscow: Progress Publishers.

Gandesha, Samir 2006, 'The "Aesthetic Dignity of Words": Adorno's Philosophy of Language', New German Critique, No. 97, pp. 137-58

Hanslick, Eduard 1957 [1854], The Beautiful in Music, Indianapolis: Bobbs-Merrill.

Kant, Immanuel 1987 [1790], Critique of Judgment, Indianapolis: Hackett.

Langer, Suzanne 1969, Philosophy in a New Key: A Study in the Symbolism of Reason, Rite, and Art, Cambridge MA: Harvard University Press.

Lecercle, Jean-Jacques 2009, A Marxist Philosophy of Language, Chicago: Haymarket.

Leppert, Richard (ed.) 2002, Essays on Music, Theodor W. Adorno, London: University of California Press.

Lerdahl, Fred and Ray Jackendoff 1983, A Generative Theory of Tonal Music, Cambridge, Mass: MIT Press.

Liikkanen, Lassi A. 2012, 'Musical activities predispose to involuntary musical imagery', Psychology of Music, 40(2), pp. 236-56

Marx, Karl 1973 [1844], Economic and Philosophical Manuscripts in Marx Engels on Literature and Art (Documents on Marxist Aesthetics I), 
edited by Lee Baxandall and Stefan Morawski, New York: International General.

Marx, Karl and Frederick Engels 1970 [1845], The German Ideology, London: Lawrence and Wishart.

McNally, David 2001, Bodies of Meaning: Studies on Language, Labor and Liberation, Albany, NY: SUNY Press.

Müller, Harro 2009, 'Mimetic Rationality: Adorno's Project of a Language of Philosophy', New German Critique, No. 108, pp. 85-108.

Nelson, Amy 2004, Music for the Revolution: Musicians and Power in Early Soviet Russia, Pennsylvania State University Press.

Paddison, Max 1991, 'The Language-Character of Music: Some Motifs in Adorno', Journal of the Royal Musical Association, Vol. 116, No. 2, pp. 267-79

Paddison, Max 1997, Adorno's Aesthetics of Music, Cambridge: University of Cambridge.

Raffman, Diana 1993, Language, Music, and Mind, Cambridge, Mass: MIT Press.

Rebuschat, Patrick et al (eds) 2012, Language and Music as Cognitive Systems, Oxford: Oxford University Press.

Rose, Jacqueline 2016, 'From the Inside out', London Review of Books 38/18, 2016.

Schopenhauer, Arthur 2010 [1818], The World as Will and Representation, Cambridge: Cambridge University Press.

Statista Research Analysis 2014, http://www.statista.com/statistics/352204/number-of-people-playmusical-instrument-usa/

Toynbee, Jason 2003, 'Music, Culture, and Creativity', in The Cultural Study of Music: a critical introduction, edited by Martin Clayton et al, London: Routledge.

Voloshinov, Valentin N. 1973, Marxism and the Philosophy of Language, Cambridge, Mass: Harvard University Press. 
Williams, Raymond 1997, Marxism and Literature, Oxford: Oxford University Press.

Williamson, Victoria J. and Sagar R. Jilka 2014, 'Experiencing earworms: An interview study of Involuntary Musical Imagery', 